\title{
Optimized method for black carbon analysis in ice and snow using the Single Particle Soot Photometer
}

\author{
I. A. Wendl ${ }^{1,2,3,{ }^{*} \text {, J. A. Menking }}{ }^{4, *}$, R. Färber ${ }^{5}$, M. Gysel ${ }^{5}$, S. D. Kaspari ${ }^{4}$, M. J. G. Laborde ${ }^{5}$, and M. Schwikowski ${ }^{1,2,3}$ \\ ${ }^{1}$ Laboratory of Radiochemistry and Environmental Chemistry, Paul Scherrer Institut, 5232 Villigen PSI, Switzerland \\ ${ }^{2}$ Oeschger Centre for Climate Change Research, University of Bern, Bern, Switzerland \\ ${ }^{3}$ Department of Chemistry and Biochemistry, University of Bern, Bern, Switzerland \\ ${ }^{4}$ Department of Geological Sciences, Central Washington University, Ellensburg, WA, USA \\ ${ }^{5}$ Laboratory of Atmospheric Chemistry, Paul Scherrer Institut, 5232 Villigen PSI, Switzerland \\ *These authors contributed equally to this work.
}

Correspondence to: M. Schwikowski (margit.schwikowski@psi.ch)

Received: 11 February 2014 - Published in Atmos. Meas. Tech. Discuss.: 28 March 2014

Revised: 27 June 2014 - Accepted: 30 June 2014 - Published: 21 August 2014

\begin{abstract}
In this study we attempt to optimize the method for measuring black carbon (BC) in snow and ice using a Single Particle Soot Photometer (SP2). Beside the previously applied ultrasonic (CETAC) and Collison-type nebulizers we introduce a jet (Apex Q) nebulizer to aerosolize the aqueous sample for SP2 analysis. Both CETAC and Apex Q require small sample volumes (a few milliliters) which makes them suitable for ice core analysis. The Apex $\mathrm{Q}$ shows the least size-dependent nebulizing efficiency in the $\mathrm{BC}$ particle diameter range of $100-1000 \mathrm{~nm}$. The CETAC has the advantage that air and liquid flows can be monitored continuously. All nebulizer-types require a calibration with $\mathrm{BC}$ standards for the determination of the $\mathrm{BC}$ mass concentration in unknown aqueous samples. We found Aquadag to be a suitable material for preparing calibration standards. Further, we studied the influence of different treatments for fresh discrete snow and ice samples as well as the effect of storage. The results show that samples are best kept frozen until analysis. Once melted, they should be sonicated for $25 \mathrm{~min}$, immediately analyzed while being stirred and not be refrozen.
\end{abstract}

\section{Introduction}

Light-absorbing impurities in snow and ice play an important role in the Earth's radiative balance and thus climate change. The main absorbers of visible solar radiation are atmospheric black carbon (BC) particles, emitted by incomplete combus- tion of biomass and fossil fuels. When deposited on snow or ice, BC lowers the albedo of the surface, leading to accelerated melt. Recently, Bond et al. (2013) reported a radiative forcing between 0.01 and $0.09 \mathrm{~W} \mathrm{~m}^{-2}$ for the snow albedo effect of BC. Furthermore, the efficacy of this forcing was found to be up to three times greater than the forcing by $\mathrm{CO}_{2}$ (Flanner et al., 2007).

Traditionally, BC concentration in snow and ice has been analyzed by filter-based methods, such as optical or thermaloptical techniques (Clarke and Noone, 1985; Dou et al., 2012; Lavanchy et al., 1999). These methods require large sample volumes usually not available from ice cores. Ice cores offer a unique medium to study the variability of BC concentrations over long time periods, but analyses that require large sample volumes result in low time (or depth) resolution. Furthermore, the filter-based methods have the potential to over- or underestimate the $\mathrm{BC}$ mass concentration due to analytical artifacts, such as charring of organic carbon (Soto-García et al., 2011), dust interference (Wang et al., 2012) or filter efficiency (Torres et al., 2014).

The Single Particle Soot Photometer (SP2, Droplet Measurement Technology, Inc., Boulder, CO, USA; Schwarz et al., 2006) has been used in snow and ice research in a variety of studies (Bisiaux et al., 2012a, b; Kaspari et al., 2011; McConnell et al., 2007; Sterle et al., 2013). The SP2 does not require a filtration step, which makes it less time-consuming than the traditional methods and enables its use in a continuous flow analysis system. The SP2 analysis requires very 
little sample volume, which allows obtaining highly timeresolved data series, even from ice cores. However, the SP2 requires an aerosolization step because it analyzes only airborne samples. This step can be incorporated in a continuous flow system (McConnell et al., 2007) or in batch analysis (Ohata et al., 2011). The SP2 response is BC-specific and not affected by particle morphology or coatings (Cross et al., 2010; Laborde et al., 2012; Moteki and Kondo, 2007; Slowik et al., 2007), though there is a small positive artifact caused by high dust loadings (Schwarz et al., 2012), which are rarely found in ice cores. Furthermore, the SP2 returns the size distribution of $\mathrm{BC}$ particles in addition to their mass concentration.

Mainly continuous flow systems have been used for measuring $\mathrm{BC}$ in ice, but the importance of discrete samples must not be underestimated because (1) poor ice core quality might make it impossible to cut undisturbed ice columns needed for continuous flow systems, (2) high dust content may cause clogging of the continuous melting system and (3) sonication of samples with high dust content, which helps to detach $\mathrm{BC}$ from the dust particle surfaces, is not easily performed with a continuous flow setup. Finally, snow sampling always results in discontinuous samples.

This study aims to provide SP2 users with a method for analyzing discrete liquid snow and ice samples. This includes the discussion of (1) the aerosolization of the aqueous samples focusing on (a) differences between the three nebulizer systems tested (ultrasonic (CETAC), jet (Apex Q) and Collison-type) and (b) the quantification of the nebulizer efficiency and $\mathrm{BC}$ losses in the system using aqueous BC reference standards; (2) the calibration of the SP2 for aqueous sample analysis; and (3) the best methods of sample treatment and sample storage.

Different terms are found in the literature for the most refractory and light-absorbing component of carbonaceous aerosols depending on the applied experimental method (e.g., black carbon (BC) or elemental carbon (EC)). In this study we applied an SP2, which utilizes laser-induced incandescence for quantitative measurements of refractory black carbon $(\mathrm{rBC})$ in single particles, which we denote $\mathrm{BC}$ throughout this manuscript.

\section{Experimental}

In this section we describe the SP2-setup for analysis of aqueous samples (particularly snow and ice) with emphasis on the use of a nebulizer to transform BC particles from an aqueous sample into a dry aerosol and transport them to the SP2. Furthermore, we describe the internal calibration of the SP2 and the basic principle for determining the $\mathrm{BC}$ mass concentration of an unknown aqueous sample.

\subsection{Nebulizer/SP2-setup}

The SP2 is an instrument widely applied in aerosol science; it uses the principle of laser-induced incandescence to measure the mass concentration and size distribution of $\mathrm{BC}$ on a particle-by-particle basis. Individual BC particles are heated to their boiling point $(\sim 4200 \mathrm{~K})$ by a continuous-wave Nd:YAG-laser. The peak intensity of the thermal radiation is proportional to the $\mathrm{BC}$ mass in the particle (Schwarz et al., 2006). The thermal radiation is detected with two photomultiplier tubes covering different wavelength ranges (broadband: 350-800 nm; narrowband: $\sim 630-800 \mathrm{~nm}$ ). Each detector has two different electronic signal amplification gains (high and low). We run the broadband and narrowband detectors with staggered gains and combine the signals from the high-gain broadband output with the low-gain narrowband output in order to maximize the detectable BC mass (per particle) range. The band ratio, calculated from the ratio of the broadband to narrowband signals, depends on the boiling-point temperature and the spectral emissivity of the incandescent material, thus providing information to distinguish BC particles from, e.g., metal particles (Stephens et al., 2003). The calibration of the SP2 was conducted up to a mass of $70 \mathrm{fg}$ BC. The measured calibration curve was linearly extrapolated to cover the full dynamic range of the incandescence detector (up to $\sim 500 \mathrm{fg}$, which corresponds to a BC mass equivalent diameter of $\sim 810 \mathrm{~nm}$ ). Moteki and Kondo (2010) showed that the SP2 calibration curves can deviate from linearity for larger BC mass, depending on the effective density of the particles. In this study, no deviation from linearity was observed up to a BC mass of $70 \mathrm{fg} \mathrm{BC}$ and the doubly charged particles indicated that this still holds with little uncertainty up to $140 \mathrm{fg} \mathrm{BC}$. Sensitivity analyses using an empirical power law calibration curve for the $\mathrm{BC}$ mass range above $100 \mathrm{fg}$, in a similar manner as applied by Schwarz et al. (2012), indicated deviations from the linear calibration approach well below the general calibration uncertainty of the SP2. This confirms that choosing a linear calibration curve is appropriate for this study. However, this would not necessarily hold, when a substantial fraction of the $\mathrm{BC}$ mass is detected at $\mathrm{BC}$ mass equivalent diameters above $1 \mu \mathrm{m}$.

The BC analysis of aqueous samples with the SP2 requires a nebulizer to aerosolize and dry the liquid before it can be measured. Primarily Collison-type and ultrasonic nebulizers have been used with the SP2. Here, we also discuss a jet nebulizer system, the Apex Q (High Sensitivity Sample Introduction System, Elemental Scientific Inc., Omaha, NE, USA). The three systems not only vary in their nebulizing principle but also in their efficiencies, i.e., the fraction of water-insoluble particles of the injected liquid sample that is successfully nebulized and ends up in the aerosol provided at the outlet of the nebulizer. In the following we describe the three nebulizer/SP2-setups (Fig. A1). 


\subsubsection{Ultrasonic nebulizer (CETAC)}

The ultrasonic nebulizer (U5000 AT, CETAC Technologies, Omaha, NE, USA), characterized by high efficiency and low sample consumption, has been used in several previous SP2 studies of BC in aqueous samples (Bisiaux et al., 2012a, b; Kaspari et al., 2011; McConnell et al., 2007; Ohata et al., 2011, 2013; Sterle et al., 2013). In the CETAC/SP2setup (Fig. A1a), the aqueous sample is pumped (peristaltic pump, polyfluoralkoxy-polymer (PFA) tubing) to a glass spray chamber where contact with an ultrasonic transducer causes the liquid containing the solid $\mathrm{BC}$ particles to become suspended as aerosol. A carrier gas (compressed air, BC-free) transports the aerosol through a heating and a cooling element, removing the liquid so that only dry particles are introduced into the SP2.

The primary benefit of the CETAC is that it allows the continuous monitoring of the maximally possible nebulizer efficiency ( $\eta_{\max }$, Eq. S12, in the Supplement). This is accomplished by using flow monitors to measure the rate at which the sample is introduced into the nebulizer and the rate at which that sample drains from the aerosol chamber. This drainage includes sample that was not nebulized as well as sample that impacted on the glass walls of the aerosol chamber before reaching the drying chamber. Characterizing the nebulizer efficiency is necessary because the performance of the ultrasonic transducer may vary during use. However, potential particle losses $\left(\varepsilon_{\text {loss }}(D)\right.$, Eq. S13, in the Supplement) cannot be quantified. Thus the CETAC has to be calibrated with a standard (hereafter referred to as external calibration as in Bisiaux et al., 2012b).

Experiments performed on the CETAC at Central Washington University (CWU), WA, USA, indicate that the optimal settings for $\mathrm{BC}$ analysis of snow and ice samples are $0.75 \mathrm{~L} \mathrm{~min}^{-1}$ purge airflow and $0.5 \mathrm{~mL} \mathrm{~min}^{-1}$ liquid-sample inflow. The aerosol is heated to $140^{\circ} \mathrm{C}$ and cooled to $3{ }^{\circ} \mathrm{C}$ to remove the water. The operating temperatures are based on recommendations from the manufacturer and are restricted because of the need to fully dry the aerosol before introducing it into the SP2. Minor temperature adjustments (140$160^{\circ} \mathrm{C}$ heating, $1-3{ }^{\circ} \mathrm{C}$ cooling) did not result in significant changes in the $\mathrm{BC}$ concentrations $\left(C_{\mathrm{SP} 2 \text {, low }}^{\eta}\right.$, Eq. S32, in the Supplement) derived from SP2 measurements. Altering the airflow to higher and lower values resulted in 10-33\% lower BC concentrations compared to normal flow. Similarly, sample inflows of $0.55 \mathrm{~mL} \mathrm{~min}^{-1}$ and higher caused steadily decreasing BC concentrations with up to $34 \%$ reduction. Changing these parameters may lead to inefficient nebulization of $\mathrm{BC}$ particles or to inefficient transport of $\mathrm{BC}$ particles to the SP2.

Repeated measurements of the same sample showed a standard deviation within $10 \%$ of the mean over time periods of days to weeks, though changes in the performance of the transducer over longer periods of months to years could lead to larger differences in $\mathrm{BC}$ concentration.

\subsubsection{Jet nebulizer (Apex Q)}

The Apex Q can be operated in self-aspirating mode, where the flow of the carrier gas (particle-free compressed air), the diameter and length of the capillary, and the geometry of the nebulizer nozzle define the liquid-sample flow. The aqueous sample is aerosolized into a heated $\left(100^{\circ} \mathrm{C}\right)$ glass cyclonic spray chamber with a jet nebulizer. The aerosol is then cooled $\left(2{ }^{\circ} \mathrm{C}\right)$ in a Peltier-cooled multipass condenser to remove the remaining water vapor before being introduced into the SP2 (Elemental Scientific Inc., 2013).

The Apex Q as applied at the Paul Scherrer Institut (PSI), Switzerland, can be run with liquid-sample flows between 10 and $700 \mu \mathrm{L} \mathrm{min}^{-1}$, requiring small sample volumes (see Sect. 3.1.2). The maximal nebulizer efficiency $\left(\eta_{\max }\right.$, Eq. S12, in the Supplement) is unknown for the Apex Q because most of the liquid not nebulized is evaporated from the heated spray chamber walls. Thus an external calibration is indispensable for quantitative liquid $\mathrm{BC}$ mass concentration determinations.

The optimal Apex Q/SP2-setup (Fig. A1b) includes an Apex Q PFA-ST MicroFlow nebulizer (ES-2040-7000) and a $1.5 \mathrm{~m}$ long PFA capillary with an inner diameter of $0.25 \mathrm{~mm}$ (ES-2042; both Elemental Scientific Inc., Omaha, NE, USA). The optimal purge airflow is $1 \mathrm{~L} \mathrm{~min}^{-1}$, which for our MicroFlow nebulizer (serial no. Apex Q PFA-ST 1322) results in a liquid-sample inflow of $0.13 \mathrm{~mL} \mathrm{~min}^{-1}$ to the Apex $\mathrm{Q}$, but may vary with time and nebulizer. Other settings and options, e.g., higher air inflow, use of a glass nebulizer and different diameters of tubing, did not result in higher $\mathrm{BC}$ concentrations and/or shorter measuring time even with higher sample consumption. The flow parameters of the Apex Q/SP2-setup are monitored manually and adjusted if necessary.

Repeated measurements of the same sample varied within one standard deviation of $15 \%$ of the mean, indicating the setup is stable.

\subsubsection{Collison-type nebulizer}

In the PSI Collison-type nebulizer, built in-house, a pressurized air stream that expands through a critical orifice causes the aqueous sample to be aspirated through a tube. The aqueous sample hits the air stream orthogonally and is sheared into droplets that are subsequently dried in a diffusion dryer and transported to the SP2 (Fig. A1c).

Collison-type systems can be built in-house which makes them inexpensive compared to other nebulizers. However, they have a high percentage of drain and thus, if no recirculation of the sample is performed, require relatively large sample volumes $(>50 \mathrm{~mL})$. Additionally, in the current design at PSI there is no control on how much sample is used because the sample is moved passively.

The Collison-type nebulizer built at PSI is run with an air pressure of 2.5 bar. The sample flow was not determined. 


\subsection{Internal calibration}

The SP2 needs empirical calibration to assign a BC mass to a given SP2 response, hereafter referred to as internal calibration. Unfortunately, the sensitivity of the SP2 differs substantially between different BC-types (Laborde et al., 2012; Moteki and Kondo, 2010). For atmospheric applications the SP2 is calibrated according to its sensitivity to BC that is typically found in ambient and diesel engine exhaust particles. This is commonly done with mass-selected fullerene soot or Aquadag (AQ) particles, applying appropriate scaling factors as recommended in Baumgardner et al. (2012). Two aspects are important for accurate quantification of $\mathrm{BC}$ mass in liquid samples. First, the SP2 must be calibrated according to its sensitivity to the BC-type under investigation. The BCtype contained in the aqueous $\mathrm{BC}$ standard may differ from that, e.g., in an ice core sample. Thus, it may be necessary to apply different SP2 calibration curves for the analysis of the $\mathrm{BC}$ standard and the ice core samples, so that the most suitable SP2 calibration is used for either BC-type. Second, it is important to account for potential non-BC matter in the SP2 calibration material in a consistent manner (see next section and Sects. S.4 and S.5 in the Supplement for details).

\subsection{Approaches to determine the $\mathrm{BC}$ mass concentration of an aqueous sample}

The nebulizer efficiency must be accounted for when determining the $\mathrm{BC}$ mass concentration in an aqueous sample via SP2 measurement of the nebulized aerosol. This can be done in two ways: (1) by determining the nebulizer efficiency or (2) by relating the measurement of the unknown sample to the measurement of an aqueous $\mathrm{BC}$ standard with known concentration (external calibration).

\subsubsection{Using known nebulizer efficiency}

If the overall nebulizer efficiency is known for all BC particle sizes, it is possible to directly infer the $\mathrm{BC}$ mass concentration in a liquid sample from the $\mathrm{BC}$ mass size distribution measured by the SP2 for the nebulized sample by using Eq. (S27) (in the Supplement). The only errors introduced with this approach arise from a potential SP2 calibration bias and missing $\mathrm{BC}$ mass from particles with a $\mathrm{BC}$ mass outside the detection range of the SP2 (Eq. S28, in the Supplement). However, this approach has to our knowledge not been used so far as the nebulizer efficiency is typically not exactly known.

The overall nebulizer efficiency depends on the fraction of nebulized sample, the liquid and air flow rates as well as the BC particle losses in the system. An upper limit for the nebulizer efficiency $\eta_{\max }$ can be calculated from the relevant flow rates (Eq. S12, in the Supplement), with the assumption that no $\mathrm{BC}$ particle losses occur. A lower limit for the $\mathrm{BC}$ mass concentration in the aqueous sample $C_{\mathrm{SP} 2 \text {,low }}^{\eta}$ is then obtained with the following (Eq. S32, in the Supplement):

$C_{\mathrm{SP} 2, \mathrm{low}}^{\eta}=\frac{1}{\eta_{\max }} c_{\mathrm{SP} 2}$,

where $c_{\mathrm{SP} 2}$ is the $\mathrm{BC}$ mass concentration of the nebulized sample measured by the SP2. This approach has previously been applied by Kaspari et al. (2011). Based on analysis of aqueous $\mathrm{BC}$ standards, $C_{\mathrm{SP} 2 \text {,low }}^{\eta}$ determined using the CETAC/SP2-setup at CWU underestimates BC concentration by at least $50 \%$ (see also Sect. S.3.2 in the Supplement). Using this method without external calibration is not advised.

\subsubsection{Using external calibration}

Commonly (Bisiaux et al., 2012a, b; Sterle et al., 2013), the nebulizer efficiency is implicitly accounted for by relating the SP2 measurement of a nebulized sample to that of an aqueous BC standard of known concentration. Two slightly different approaches can be chosen.

\section{Approach 1}

The nebulizer efficiency is assumed to remain stable between measurement of the sample and the standard. With this approach, the $\mathrm{BC}$ mass concentration in the aqueous sample under investigation $C_{\mathrm{SP} 2}^{\mathrm{S} 1}$ is calculated as follows (Eq. S35, in the Supplement):

$C_{\mathrm{SP} 2}^{\mathrm{S} 1}:=c_{\mathrm{SP} 2} \frac{C_{\mathrm{liq}}^{*}}{c_{\mathrm{SP} 2}^{*}}$,

where $c_{\mathrm{SP} 2}$ and $c_{\mathrm{SP} 2}^{*}$ are the $\mathrm{BC}$ mass concentrations measured by the SP2 for the aerosols from the nebulized aqueous sample and aqueous standard, respectively, and $C_{\text {liq }}^{*}$ is the BC mass concentration of the aqueous standard.

This approach can be applied for any nebulizer with a stable efficiency, e.g., the Apex Q and the Collison-type. The inferred, $C_{\mathrm{SP} 2}^{\mathrm{S} 1}$, and true, $C_{\text {liq }}$, $\mathrm{BC}$ mass concentrations of the aqueous sample relate to each other as follows (Eq. S42 in the Supplement):

$C_{\mathrm{SP} 2}^{\mathrm{S} 1}=C_{\text {liq }} \frac{f_{\text {bias }}}{f_{\text {bias }}^{*}} k_{\mathrm{S} 1}$.

The result is biased if the sensitivity of the SP2 to the BCtypes in the sample and/or standard is unknown; thus, the respective SP2 calibration bias factors $f_{\text {bias }}$ and/or $f_{\text {bias }}^{*}$ will be different from unity (see Eq. S16 in the Supplement for definition of $f_{\text {bias }}$ ). This restricts the choice of internal calibration standards to BC-types for which the SP2 sensitivity is known $\left(\Rightarrow f_{\text {bias }}^{*}=1\right)$. The factor $f_{\text {bias }}$ only becomes unity if the sensitivity of the SP2 to the BC-type in the sample is known, therefore potentially leaving some uncertainty. Note that it does not matter whether the SP2's sensitivity is equal or different for the standard and sample nor does it have any 
influence on the resulting uncertainty of the method if appropriate calibration curves are chosen for the analysis of both measurements. The reason for this is that, in this approach, the measurement of the standard is solely used to quantify the efficiency of the nebulizer, while it is not used to quantify the sensitivity of the SP2.

The factor $k_{\mathrm{S} 1}$ in Eq. (3) is given in Eq. (S43) (in the Supplement). It shows that additional errors can potentially be introduced due to the following two reasons: (1) if a substantial portion of the BC mass size distribution of the sample and/or the standard falls outside the detection range of the SP2 or (2) if the nebulizer efficiency depends on the size of the $\mathrm{BC}$ particles. The bias introduced by the latter only disappears if the nebulizer efficiency is independent of size or if the $\mathrm{BC}$ size distributions of the sample and standard have equal shape. The stronger the size-dependence of the nebulizer efficiency and the more different the size distribution shapes, the larger the bias introduced by the second reason (see Sect. S.2 in the Supplement for details).

This approach is applied to the Apex Q/SP2- and the Collison-type/SP2-setups at PSI.

\section{Approach 2}

Drifts of the liquid sample and/or air flow rates between the measurement of the standard and the sample will result in a drift of the nebulizer efficiency. If these flows are monitored, this can be accounted for by using the following equation to infer the $\mathrm{BC}$ mass concentration $C_{\mathrm{SP} 2}^{\mathrm{S} 2}$ of the liquid sample (Eq. S37, in the Supplement):

$C_{\mathrm{SP} 2}^{\mathrm{S} 2}:=C_{\mathrm{SP} 2, \text { low }}^{\eta} \frac{C_{\text {liq }}^{*}}{C_{\mathrm{SP} 2, \text { low }}^{\eta, *}}$,

where $C_{\mathrm{SP} 2 \text {,low }}^{\eta}$ and $C_{\mathrm{SP} 2 \text {, low }}^{\eta, *}$ are the lower limit of the $\mathrm{BC}$ mass concentration in the aqueous sample and standard, respectively, as inferred using Eq. (1).

This approach is applied for the CETAC/SP2-setups at CWU and PSI.

The approaches 1 and 2 are identical if the flow rates do not drift, and the caveats made for approach 1 regarding biases introduced by using an external calibration also apply to approach 2 (see also Eqs. S44 and S45 in the Supplement). The external calibration factor $C_{\mathrm{liq}}^{*} / C_{\mathrm{SP} 2, \text { low }}^{\eta, *}$ for approach 2 (or $C_{\mathrm{liq}}^{*} / c_{\mathrm{SP} 2}^{*}$ for approach 1) can be determined with a single measurement of a suitable standard. We determined this ratio from a series of measurements of different standards with concentrations in the range of $C_{\text {liq }}^{*}=0.5$ to $\sim 14 \mu \mathrm{g} \mathrm{L}-1$ (for details on the preparation, see Sect. 2.4.1). The results are given in Table 1, where the values correspond to the slope of the linear regression through the correlation of $C_{\mathrm{liq}}^{*}$ with $C_{\mathrm{SP} 2, \text { low }}^{\eta, *}$ for each standard, using the internal SP2 calibration as indicated in the column header.
Table 1. External calibration factor $\left(C_{\mathrm{liq}}^{*} / C_{\mathrm{SP} 2, \mathrm{low}}^{\eta, *}\right)$ for the CETAC determined by using various BC-like materials. n.a. stands for not applicable.

\begin{tabular}{|c|c|c|}
\hline $\begin{array}{l}\text { BC-like } \\
\text { Material }\end{array}$ & $\begin{array}{r}\text { Linear fit of } \\
C_{\mathrm{liq}}^{*} / C_{\mathrm{SP} 2, \text { low }}^{\eta, *} \\
(\mathrm{mean} \pm 1 \sigma) \text { internal } \\
\text { calibration with AQ }\end{array}$ & $\begin{array}{r}\text { Linear fit of } \\
C_{\mathrm{liq}}^{*} / C_{\mathrm{SP} 2, \text { low }}^{\eta * *} \\
(\text { mean } \pm 1 \sigma) \text { internal } \\
\text { calibration with fullerene soot }\end{array}$ \\
\hline AQ & $3.4 \pm 0.7$ & n.a. \\
\hline Aquablack & $5.0 \pm 2.4$ & $3.0 \pm 1.3$ \\
\hline Cabojet & $3.9 \pm 0.6$ & $2.2 \pm 0.3$ \\
\hline Flame soot & $4.5 \pm 0.5$ & $2.3 \pm 0.3$ \\
\hline Fullerene soot & n.a. & $2.0 \pm 0.3$ \\
\hline
\end{tabular}

\subsection{Standard preparation}

\subsubsection{BC standards}

In order to determine uncertainties associated with using the external calibration approach and to identify the suitable materials as standard for external calibration we prepared standards with $C_{\text {liq }}^{*}$ ranging from 0.5 to $14 \mu \mathrm{g} \mathrm{L}^{-1}$ using different BC-like materials (AQ, Aquablack 162, Cabojet 200, flame soot and fullerene soot), similar to the procedure described below for AQ. The actual BC content of each material was considered in the calculation of the concentration: $\sim 71 \%$ for AQ, $74 \%$ for Aquablack, $88 \%$ for Cabojet and $100 \%$ for fullerene (Gysel et al., 2011; S. Ohata, personal communication, 2013) and flame soot (T. Kirchstetter, personal communication, 2012) (Table B1).

AQ is an industrial lubricant consisting of a colloidal suspension of aggregates of graphitic carbon in water with $\sim 70.5 \% \pm 1.0 \%(1 \sigma) \mathrm{BC}$ content of the dry mass $(76 \%$ in Gysel et al., 2011). The dry mass needs to be determined for each batch because the moisture content may vary between batches and AQ can dry over time.

We prepared a stock with a $\mathrm{BC}$ mass concentration of $2500 \mu \mathrm{g} \mathrm{L}-1$ in a $1 \mathrm{~L}$ glass volumetric flask. The standards were diluted by mass from this stock immediately prior to analysis. After sonicating the $2500 \mu \mathrm{g} \mathrm{L}^{-1}$ stock for $20 \mathrm{~min}$, we prepared a $100 \mu \mathrm{g} \mathrm{L}^{-1}$ stock in a $50 \mathrm{~mL}$ polypropylene (PP) vial. Then we created standards of $0.5-14 \mu \mathrm{g} \mathrm{L}{ }^{-1} \mathrm{BC}$ in individual $50 \mathrm{~mL}$ PP vials $\left(\geq 5 \mu \mathrm{g} \mathrm{L}^{-1}\right.$ standard diluted from the $2500 \mu \mathrm{g} \mathrm{L}^{-1}$ stock; $\leq 2 \mu \mathrm{g} \mathrm{L}{ }^{-1}$ standard diluted from the $100 \mu \mathrm{g} \mathrm{L}^{-1}$ stock).

\subsubsection{Polystyrene latex sphere (PSL) standards}

In order to investigate the size-dependence of the nebulizer efficiency (Sect. 3.1), we prepared standards of polystyrene latex spheres (PSL). We used PSLs with diameters of 100, 150, 269, 350, 450, 600, 800 and $1000 \mathrm{~nm}$ (Duke Scientific Corp., CA, USA) at PSI and diameters of 220, 356, 505, 771 and $1025 \mathrm{~nm}$ (Polyscience Inc., Warrington, PA, USA) at CWU. For a known PSL number concentration 
in water, we used the solid weight percentage determined by drying (on average $1.2 \% \pm 0.2 \%$ for the Duke PSLs) and provided by the manufacturer $(7 \%$ for the Polyscience PSLs; Schwarz et al., 2012) and calculated the number concentrations according to Eq. (1) in Schwarz et al. (2012). These ranged from $2.65 \times 10^{6}$ to $2.48 \times 10^{9}$ particles $\mathrm{cm}^{-3}$ for the Duke PSL standards, which were diluted further (at least 1:5) for analysis with the CETAC and Apex Q/SP2setups. The Polyscience PSLs ranged from $1.5 \times 10^{5}$ to $7.9 \times 10^{5}$ particles $\mathrm{cm}^{-3}$.

\subsubsection{Snow and ice samples}

We used several snow and ice samples to monitor the stability of the setup and to test the optimal method on real samples. The so-called internal snow standards were prepared from fresh snow from Blewett Pass, WA, USA, and from Ewigschneefeld, Switzerland. A large amount of fresh snow was melted and kept in a glass bottle in the refrigerator $\left(\sim 5^{\circ} \mathrm{C}\right)$. The ice core samples used for testing the optimal method include two core segments from an ice core from Tsambagarav Glacier, Mongolian Altai, drilled at $4130 \mathrm{~m}$ a.s.l. in 2009 , and two core segments from Lomonosovfonna, Svalbard, Norway, drilled at $1202 \mathrm{~m}$ a.s.l. in 2009. Those two ice cores are thought to represent the extremes in terms of mineral dust content with the Mongolian core being highly influenced by dust from the nearby deserts and the Svalbard core being remote from any large dust source. The dust content was estimated based on the average calcium concentration in the core segments.

\section{Results and discussion}

First, we compare the three different nebulizers tested regarding their nebulizer efficiency, which was previously indicated to be size-dependent (Ohata et al., 2013; Schwarz et al., 2012), followed by the differences in sample consumption. Second, we discuss the choice of a standard material for the external calibration. Third, we quantify the repeatability of the external calibration. Finally, we focus on (1) sample treatment, (2) sample storage and (3) recovery of BC in stored samples.

\subsection{Nebulizer comparison}

\subsubsection{Size-dependence of the nebulizer efficiency}

The nebulizer efficiencies for different particle sizes were determined by measuring the PSL standards of known number concentration described in Sect. 2.4.2 with the three nebulizer/SP2-setups (Eq. S5 in the Supplement). We extend previous studies (Ohata et al., 2013; Schwarz et al., 2012) by introducing a jet nebulizer and analyzing BC standards. At PSI all three nebulizer-types were tested, whereas only a CETAC was tested at CWU.
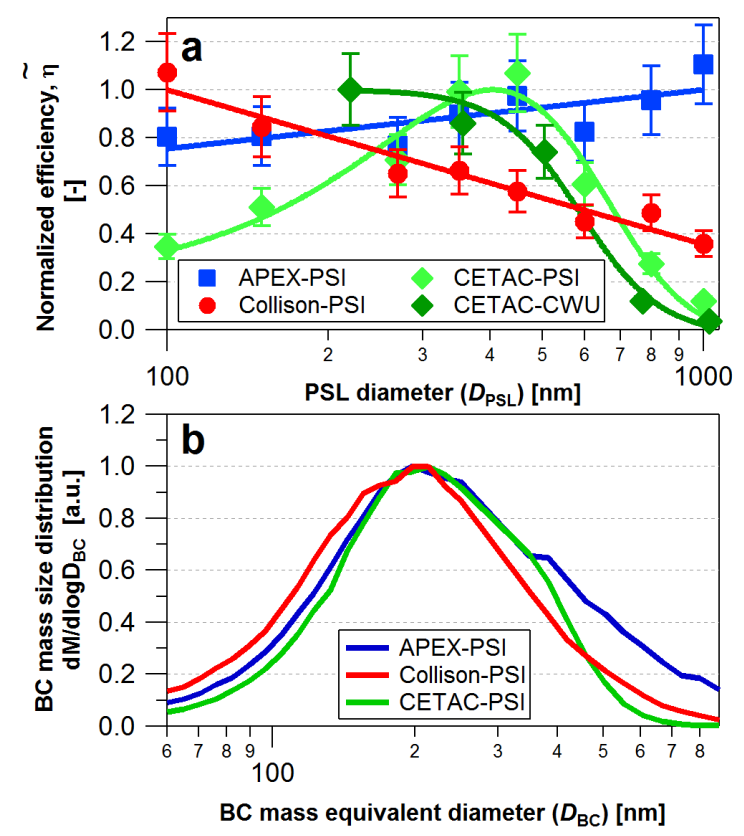

Figure 1. Comparison of the nebulizer efficiencies for the three different setups (CETAC, Apex Q and Collison-type nebulizer) for particle diameters from 100 to $\sim 1000 \mathrm{~nm}$. (a) Nebulizer efficiency for PSL standards of known number concentration; curves normalized to their maximum. (b) BC mass size distribution of polydisperse Aquadag as measured in the three setups; curves normalized to their maximum. a.u. stands for arbitrary units.

As illustrated in Fig. 1a the CETAC has a decreased efficiency not only in the large ( $>500 \mathrm{~nm}$ ) (Schwarz et al., 2012) but also in the small size range $(<200-250 \mathrm{~nm})$, similar to findings by Ohata et al. (2013). The Collison-type nebulizer shows a decreased efficiency in the large size range, whereas the Apex Q gives a size-independent efficiency for the tested size range from 100 to $1000 \mathrm{~nm}$ within the variability of the whole setup (15\%).

We further tested the three nebulizers in terms of behavior towards a commercially available BC standard, namely $\mathrm{AQ}$. The $\mathrm{BC}$ mass size distribution of polydisperse AQ, normalized to the maximum, as measured with the three setups (Fig. 1b), shows that the Collison-type nebulizer skews the BC mass concentration towards smaller sizes, compared to the Apex Q with a size-independent efficiency, and the CETAC reduces the tails of the size distribution at either end. This indicates that the size-dependence of the nebulizer efficiencies determined for PSLs (Fig. 1a) also applies to AQ particles, at least qualitatively. Relating the shape of the AQ size distribution measured by the Collison-type nebulizer to that measured by the Apex Q allows estimating the nebulizer efficiency of the Collison-type nebulizer for AQ as a function of BC mass equivalent diameter (Eq. S67 in the Supplement) and mobility diameter (Eq. S72 in the Supplement), making use of the weak size-dependence of the Apex Q nebulizer efficiency, which justifies the respective assumptions made in 


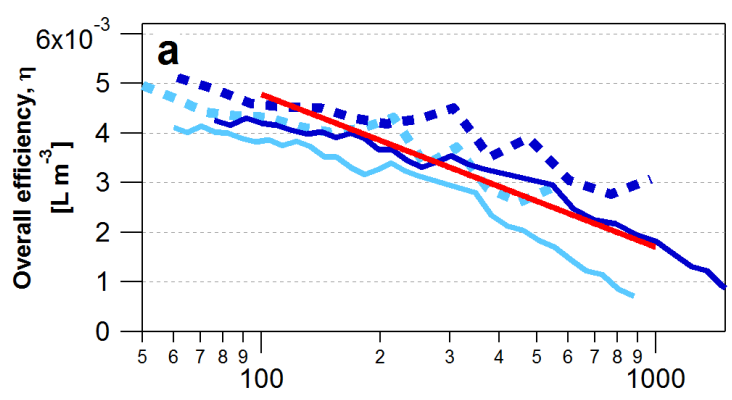

Diameter $\left(D_{\mathrm{PSL}}, D_{\mathrm{BC}}\right.$, or $\left.D_{\mathrm{mob}}\right)[\mathrm{nm}]$

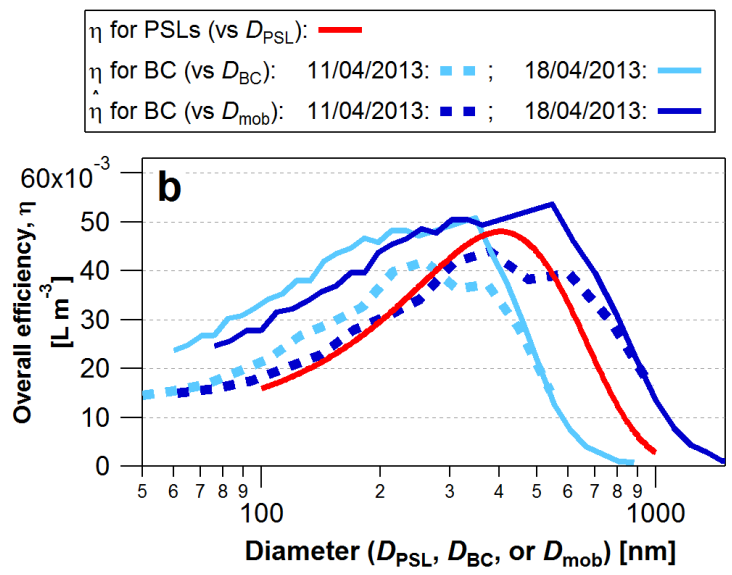

Figure 2. Overall nebulizer efficiency of (a) the Collison-type nebulizer and (b) the PSI-CETAC nebulizer for PSLs and polydisperse Aquadag (AQ) relative to that of the Apex $\mathrm{Q}$ on two different days. $D_{\text {PSL }}$ represents PSL diameter; $D_{\mathrm{BC}}$ stands for BC mass equivalent diameter; $D_{\text {mob }}$ is mobility diameter.

Eqs. (S66) and (S71) in the Supplement. Figure 2a shows that the efficiency of the Collison-type nebulizer for $\mathrm{BC}$ is equal to that for PSLs within the repeatability of this approach, whereas the relevant particle diameter that determines the losses for the BC particles is likely somewhere between the mass equivalent and the mobility diameter. Based on this finding it would be justified to use the nebulizer efficiency inferred from PSL measurements to quantify the BC mass concentration of an unknown sample by using the approach of Sect. 2.3.1.

The efficiency of the PSI-CETAC for BC was determined in the same manner. Figure $2 b$ reveals that the nebulizer efficiency has the same shape and magnitude for BC and PSLs. However, there is a substantial and size-dependent shift in diameter both when using the mass equivalent or the mobility diameter for BC particles. This makes it difficult to impossible to accurately infer the efficiency for $\mathrm{BC}$ from that for PSLs. Thus, applying Eq. (S27) (in the Supplement) to quantify the BC mass concentration of an unknown sample would be associated with considerable uncertainty when using a nebulizer with a very strongly size-dependent efficiency such as the CETAC.

\subsubsection{Sample consumption}

Sample consumption is crucial, especially when working with ice cores of limited volume. The Collison-type nebulizer at PSI requires sample volumes $>50 \mathrm{~mL}$, whereas both the CETAC and Apex Q need relatively small sample volumes. In the case of our AQ standards this was $<3 \mathrm{~mL}$, which can be used as a guide value, although it may vary depending on whether the particle size distribution of the sample differs strongly from that of $\mathrm{AQ}$.

Generally, the amount of sample volume required is determined by the recommendation to record $\sim 10000 \mathrm{BC}$ containing particles (Schwarz et al., 2012) to ensure statistical precision of the measurement. We can only support this recommendation although it may take more than an hour to record 10000 particles with the Apex Q. If this is not feasible with one sample in terms of available sample volume and measuring time, it is possible to combine adjacent samples at the expense of temporal resolution.

The comparison of the three nebulizers suggests the Apex $\mathrm{Q}$ to have the most size-independent nebulizing efficiency, making it the most suitable nebulizer for BC analysis of snow and ice samples using a nebulizer/SP2-setup. However, the nebulizing efficiency of the Apex $\mathrm{Q}$ has to be assumed to be constant, whereas with the CETAC it can be continuously monitored.

Later on in the paper, we exclude the Collison-type nebulizer from the discussion because its high sample consumption makes it unsuitable for the analysis of snow and ice samples.

\subsection{Uncertainty of external calibration approach and choice of $\mathrm{BC}$ standard material}

The standards of different BC-like materials (AQ, Aquablack 162, Cabojet 200, flame soot and fullerene soot; see Sect. 2.4.1 for preparation procedure) were analyzed with the CETAC/SP2-setup at CWU to determine the external calibration factor $C_{\mathrm{liq}}^{*} / C_{\mathrm{SP} 2, \text { low }}^{\eta, *}$ for the second approach of external calibration (Sect. 2.3, Eq. 4), which accounts for flow rate drifts.

The sensitivity of the SP2 to the BC-type in Aquablack, Cabojet and flame soot is not known; therefore, $c_{\mathrm{SP} 2}$ was determined with both AQ and fullerene soot internal calibration data (Sects. 2.2 and S.5 in the Supplement). Thus two columns with different $C_{\mathrm{liq}}^{*} / C_{\mathrm{SP} 2 \text {, low }}^{\eta, *}$ are given in Table 1 . In the cases of AQ and fullerene soot only the AQ and fullerene soot internal calibration, respectively, were applied. The BC content of AQ (71\% BC) was accounted for in the AQ internal calibration applied to obtain the values in the first data column of Table 1. The BC content was also accounted for in the calculation of $C_{\text {liq }}^{*}$ for the AQ standards in order to treat it consistently (see Sect. S.4 in the Supplement). Fullerene soot standards were analyzed 1 year after the AQ, Aquablack, Cabojet and flame soot standards. AQ standards analyzed at 


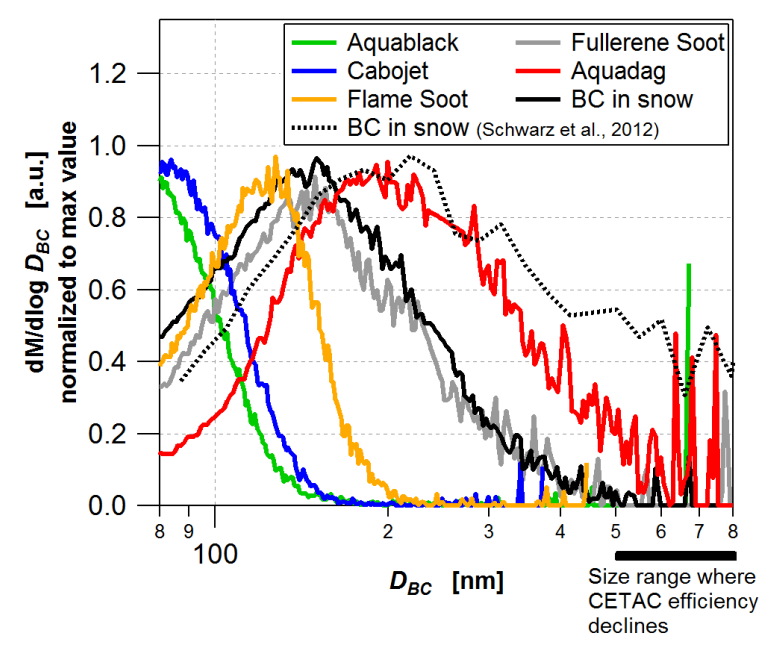

Figure 3. Average mass size distributions of various BC materials measured with the CETAC/SP2-setup at CWU - Aquadag, Cabojet 200, Aquablack 162, flame soot, fullerene soot and BC in snow (Blewett Pass, WA, USA). Large particles were allowed to settle out of the fullerene soot sample prior to measurement according to Schwarz et al. (2012). The curve from Schwarz et al. (2012) is added to illustrate the variability of the BC mass size distribution in snow. The lower limit of the horizontal axis is set at $80 \mathrm{~nm}$ because this is the lower limit of reliable internal calibration and detection efficiency of the SP2.

the same time as fullerene soot indicated a shift with time in the losses $\left(\varepsilon_{\text {loss }}(D)\right.$, Eq. S9 in the Supplement) occurring in the CETAC nebulizer. The $C_{\mathrm{liq}}^{*} / C_{\mathrm{SP} 2 \text {, low }}^{\eta, *}$ reported for fullerene soot in Table 1 is adjusted based on the shift of $C_{\text {liq }}^{*} / C_{\mathrm{SP} 2, \text { low }}^{\eta, *}$ of $\mathrm{AQ}$ analyzed during both experiments.

The values reported in Table 1 reveal that the external calibration factor of the CETAC determined with different standards spans a range of more than a factor of two. Consequently, the $\mathrm{BC}$ mass concentrations determined for an unknown aqueous BC sample by using the nebulizer/SP2setup and the external calibration approach are potentially associated with large uncertainties. The reasons for this spread arise, e.g., from SP2 calibration uncertainties, detection range limitations of the SP2 and the size-dependence of nebulizer losses (quantified by $k_{\mathrm{S} 2} / f_{\text {bias }}^{*}$ in Eq. (S44) (in the Supplement), which is essentially equal to Eq. 3). Uncertainties in standard preparation, i.e., in $C_{\mathrm{liq}}^{*}$, also contribute though the exact share remains unknown without a method to independently determine the true $C_{\text {liq }}^{*}$.

The sensitivity of the SP2 to the BC-type in Aquablack, Cabojet and flame soot is unknown, introducing a difference of a factor of $\sim 1.8$ between possible external calibration values, assuming that the extremes of SP2 sensitivity are represented by fullerene soot and that AQ accounted for the non$\mathrm{BC}$ fraction. Therefore, Aquablack, Cabojet and flame soot are not recommended as calibration standard.

Even if the SP2 sensitivity was known, Aquablack and Cabojet would remain unsuitable for external calibration as $\sim 50 \%$ or more of the $\mathrm{BC}$ mass is associated with $\mathrm{BC}$ core sizes below the lower detection limit of the SP2 (Fig. 3). This results in underestimation of $C_{\mathrm{SP} 2, \text { low }}^{\eta, *}$, overestimation of the external calibration factor and thus also the $\mathrm{BC}$ concentration that would be inferred for an unknown sample by using Eq. (4).

For both AQ and fullerene soot the SP2 sensitivity is known and the dominant fraction of their mass size distributions lies between the upper and lower detection limit of the SP2 in terms of BC core size. Despite this, the external calibration factor determined for the CETAC is $\sim 70 \%$ smaller for the fullerene soot compared to the AQ standard. This difference is mainly caused by the strong size-dependence of the CETAC nebulizer efficiency with a sharp drop above $\sim 500 \mathrm{~nm}$. AQ has a larger contribution of bigger BC particles compared to fullerene soot (Fig. 3) and thus the external calibration factor shown in Table 1 , which is essentially an inverted average of the nebulizer losses $\varepsilon_{\text {loss }}^{*}\left(D_{\mathrm{BC}}\right)$ integrated over all diameters with the shape of the BC mass size distribution of the standard as a weighting function (see Eq. S74 in the Supplement), becomes larger for AQ. This influence of the shape of the $\mathrm{BC}$ mass size distribution of the standard disappears for a nebulizer with a size-independent efficiency, such as the Apex Q, thereby strongly reducing the uncertainties associated with the external calibration approach. If a nebulizer with a strongly size-dependent efficiency, such as the CETAC, is used, it is important to choose a standard which best matches the shape of the BC mass size distribution of the sample, in order to minimize the uncertainties associated with size effects. This can sometimes be AQ and sometimes fullerene soot (Fig. 3). One advantage of AQ is that it does not exhibit any batch-to-batch variability of the corresponding internal SP2 calibration curves like fullerene soot does (Gysel et al., 2011; Laborde et al., 2012).

We chose AQ to prepare the aqueous BC standards because (1) its mass equivalent diameter distribution falls almost entirely into the detection range of the SP2 $(\sim 70$ $700 \mathrm{~nm}$ ), (2) besides fullerene soot, AQ is the only standard which extends to BC diameters above $\sim 200 \mathrm{~nm}$ as is expected in snow and ice samples (Fig. 3) and (3) it is easy to weigh, suspend and dilute.

\subsection{Repeatability of external calibration}

The external calibration of the nebulizer efficiency is crucial when quantifying the $\mathrm{BC}$ mass concentration in a liquid sample by measurement of $\mathrm{BC}$ in the nebulized aerosol. We determined the repeatability of the external calibration by analyzing freshly prepared AQ standards from two different concentrated $2500 \mu \mathrm{g} \mathrm{L}{ }^{-1}$ stocks over a period of 2 months, using both the CETAC/SP2- and Apex Q/SP2-setups. The reproducibility was within $\sim 19 \%$. This includes the uncertainty in concentrations of the stock and the diluted standards and the uncertainty of the whole nebulizer/SP2-setup. These tests also revealed that the $2500 \mu \mathrm{g} \mathrm{L}^{-1}$ stocks remained 
stable over the whole 2 months, whereas the $100 \mu \mathrm{g} \mathrm{L}-1$ stocks experienced significant BC losses within as little as 1 day. This demonstrates the need to prepare lower concentration stocks and standards immediately prior to analysis.

Importantly, the SP2 response to AQ scaled linearly with concentration for both systems. The external calibration factor $C_{\text {liq }}^{*} / C_{\mathrm{SP} 2, \text { low }}^{\eta, *}$ for approach 2, applied with the CETAC, was determined from the slope of the regression line through $C_{l i q}^{*}$ vs. $C_{\mathrm{SP2} \text {, low }}^{\eta, *}$ each time a dilution series was measured (and likewise $C_{\mathrm{liq}}^{*} / c_{\mathrm{SP} 2}^{*}$ for approach 1 with the Apex Q). These "averaged" external calibration factors of each dilution series varied in the 2 months by $\sim 22 \%$ for the CETAC and by $\sim 8 \%$ for the Apex Q. Additionally, environmental snow samples from Blewett Pass, WA, USA, and Ewigschneefeld, Switzerland, were used to track the stability of the CETAC/SP2-setup at CWU to identify whether dayto-day variations in the AQ external calibration factors were due to changes in nebulizer efficiency and/or SP2 response or errors in gravimetric AQ standard preparation. It is not known why the variability of AQ calibration curve slopes is higher for the CETAC than the Apex Q, but the liquid BC mass concentration of the environmental snow samples varied less than the AQ standards $\left(<9 \%, 2.56 \pm 0.21 \mu \mathrm{g} \mathrm{L}^{-1}\right.$ for Blewett snow and $1.03 \pm 0.09 \mu \mathrm{g} \mathrm{L}^{-1}$ for Ewigschneefeld snow), indicating that some portion of the $22 \%$ calibration variability may be due to errors in AQ standard production rather than variability in the CETAC/SP2-setup. SP2 users are therefore advised to use a combination of AQ and environmental snow standards and perform a calibration at least once per week. For the Apex Q/SP2-setup a weekly calibration with AQ seems sufficient.

Blank values for the CETAC/SP2-setup are $0.01 \pm 0.01 \mu \mathrm{g} \mathrm{L}^{-1}$ for ultrapure water and $0.03 \pm 0.01 \mu \mathrm{g} \mathrm{L}^{-1}$ for ultrapure ice, prepared with the same cutting process as the ice core samples. The corresponding blanks for the Apex Q/SP2-setup are $0.07 \pm 0.07 \mu \mathrm{g} \mathrm{L}^{-1}$ and $0.10 \pm 0.01 \mu \mathrm{g} \mathrm{L}^{-1}$ for ultrapure ice.

The calibration factors discussed in this section are unique to each nebulizer/SP2-setup and may shift over time due to changes in the nebulizer efficiency. As such, the relationship between $C_{\mathrm{SP} 2 \text {,low }}^{\eta}$ or $c_{\mathrm{SP} 2}$ and $C_{\text {liq }}^{*}$ must be monitored regularly. For nebulizers with a strongly size-dependent efficiency such as the CETAC, it may be necessary to choose between different standard materials to match the $\mathrm{BC}$ size distribution of the samples under investigation as well as possible (see Sect. 3.2).

\subsection{Sample treatment}

\subsubsection{Treatment of fresh samples}

In order to optimize the $\mathrm{BC}$ analysis with the SP2 several methods of sample treatment were tested, keeping all other parameters, e.g., liquid and air flows as well as pressure, stable. The results shown are applicable to freshly melted or prepared discrete samples and may not be relevant for continuous flow systems. The gains or losses in signal reported below are always relative to the signal without treatment.

First, we tested different vial materials including glass, PFA, PP, Nalgene ${ }^{\circledR}$-PP and high-density polyethylene (PEHD). Dilution series of the AQ standard were created in each type of material using the same material from the highconcentration stock to the lowest AQ standard $\left(0.5 \mu \mathrm{g} \mathrm{L}^{-1}\right)$. Each stock was sonicated for 20 min before dilution. The diluted AQ standards were then sonicated again for $25 \mathrm{~min}$ directly prior to analysis. Both standard creation and analysis was done within 1 day. The different vial materials resulted in $<10 \%$ variability. The CETAC did not nebulize liquids that had been sonicated in PFA vials. So far, we do not understand this effect. Maybe a change of surface tension of the sample in the PFA vial hinders the sample from being nebulized with the ultrasonic membrane.

Second, we investigated the effect of stirring AQ standards as well as snow and ice core samples during the measurement with a magnetic stir bar. Stirring is assumed to result in more representative sampling because it hampers settling. The ice core samples originate from Svalbard and Mongolia, and each location provided a sample with a high (92.9 and $\left.425.9 \mu \mathrm{g} \mathrm{L}^{-1}\right)$ and a low ( 24.5 and $157 \mu \mathrm{g} \mathrm{L}^{-1}$ ) calcium concentration, representing two extremes of mineral dust content. Nevertheless, the dust was not visible by eye in any sample. The results of agitating the samples were inconclusive, although previous results recommended the use of a stir bar, especially for samples with high dust loads (Kaspari et al., 2011). The effect of stirring might vary in the case of samples with even higher dust content.

Third, we tested the same samples for the effect of sonication prior to analysis by varying the sonication time from 0 to $50 \mathrm{~min}$. Sonication can break down agglomerates which might cause interferences in the SP2. The results showed that 25 min sonication increases the BC mass concentration insignificantly $(\sim 5 \% \pm 22 \%)$ and that sonication for different amounts of time gave inconclusive results.

Fourth, we examined the effect of a combination of stirring and sonication with the same samples as above. A $\sim 15 \% \pm 21 \%$ increase in the measured BC mass concentration indicates the optimal treatment to be the combination of sonication for $25 \mathrm{~min}$ and stirring.

Fifth, we investigated the effect of acidification of the samples to $0.5 \mathrm{M}$ with $65 \%$ suprapur nitric acid $\left(\mathrm{HNO}_{3}\right)$ as proposed by Kaspari et al. (2011). This effect may depend on the sample composition, as indicated by varying results with AQ standards and snow and ice samples. Since precise sample composition is not known for snow or ice samples and acidification causes $\sim 22 \% \pm 14 \%$ lower measured BC mass concentrations, we do not advise acidification.

These results indicate that the vial material used for fresh samples may be chosen based on practicability. We use PP vials that are (1) easy to handle in the cold room, (2) large enough to hold the obtained ice samples, (3) lighter and safer 
in the field than glass and (4) low-cost, which is important especially if sampling at high resolution. Since all tests beside that of the sonication for different time periods include 25 min sonication (Kaspari et al. (2011) suggested $15 \mathrm{~min}$ ), we recommend sonicating the samples for $25 \mathrm{~min}$ plus stirring of the samples with a magnetic stir bar during sample analysis.

\subsubsection{Sample storage}

Repeated measurements of previously melted snow samples indicate that the $\mathrm{BC}$ concentration of samples stored in the liquid phase are not stable over time. We assessed the stability of liquid samples and determined the most stable conditions for their storage prior to SP2 analysis. In some cases it might be desirable to measure the $\mathrm{BC}$ concentration of aqueous samples that have been previously melted, e.g., archived samples or samples from remote locations that melted during retrieval. Furthermore, it is preferable to store BC standards created in the liquid phase for repeat use if they remain stable.

Liquid suspensions of the $\mathrm{BC}$-like materials $\mathrm{AQ}$, Aquablack, Cabojet and flame soot as well as environmental snow samples were stored in PP and glass vials at 25 and $2{ }^{\circ} \mathrm{C}$. The liquid $\mathrm{BC}$ mass concentration of the samples was measured immediately after standard creation or melting of the snow, using the CETAC/SP2-setup. The concentrations were monitored for 18 days. Samples stored in glass vials at $2{ }^{\circ} \mathrm{C}$ showed no significant losses, whereas samples stored in PP vials at $25^{\circ} \mathrm{C}$ showed the highest losses of $30-80 \%$. Samples stored in glass vials at $25^{\circ} \mathrm{C}$ and PP vials at $2{ }^{\circ} \mathrm{C}$ experienced variable $\mathrm{BC}$ losses $(0-20 \%)$. These results were consistent for all $\mathrm{BC}$ reference materials as well as the snow samples (see Appendix C for data and details). We assume that $\mathrm{BC}$ losses in aqueous samples are due to particles adhering to vial walls or agglomerating to larger sizes outside of the SP2 detection range.

Melted ice core samples are often refrozen for preservation after the first measurement. Aqueous samples of snow were refrozen to see if this procedure affects BC stability during storage. Refreezing and thawing snow samples after the first melt resulted in BC losses of up to $60 \%$. A second freezethaw cycle resulted in further losses of the same magnitude. Losses from refreezing may be due to the agglomeration of $\mathrm{BC}$ particles to larger sizes not entering the system or not being detected by the SP2 when the particles are rejected by the matrix of ice crystals (Schwarz et al., 2013). However, like Schwarz et al. (2012), we did not observe significant shifts in the mass size distribution of samples that underwent freezethaw cycles.

We also tested whether acidification affected sample stability during storage. We acidified snow samples and samples of $\mathrm{AQ}$ of $\sim 4, \sim 10$ and $\sim 24 \mu \mathrm{g} \mathrm{L}^{-1} \mathrm{BC}$ to $0.5 \mathrm{M}$ using $65 \%$ suprapur $\mathrm{HNO}_{3}$ immediately after melting (snow) or preparing (AQ) the samples. The BC concentration of each sample was measured directly after acidification and during the following 13 days. We found that acidification did not halt or slow BC losses when those samples were stored in the liquid phase. Additionally, acidification caused immediate losses of up to $\sim 35 \%$ in all of our AQ samples.

Overall, we advise keeping snow and ice samples frozen until prior to BC analysis with the SP2. If this cannot be fulfilled, samples should be stored in glass vials at cold temperature $\left(\sim 2{ }^{\circ} \mathrm{C}\right)$, though monitoring samples for longer than 18 days (multiple months) suggests that losses might still occur under these conditions (results not shown). Thus measurements of samples stored in the liquid phase may underestimate the actual BC mass concentration. Samples should further not be refrozen or acidified since these procedures lead to $\mathrm{BC}$ losses.

\subsubsection{Recovery of $\mathrm{BC}$ in stored samples}

We tested whether the $\mathrm{BC}$ mass concentration of samples could be recovered after undergoing losses in storage. Samples that had experienced $\mathrm{BC}$ losses during storage were treated with (1) acid $\left(\mathrm{HNO}_{3}\right)$ and (2) a dispersing agent (sodium pyrophosphate decahydrate). Kaspari et al. (2011) suggested acidifying samples in order to recover BC lost during refreezing, but our results do not support acidification. Sixteen samples were acidified to $0.5 \mathrm{M}$ with $65 \%$ suprapur $\mathrm{HNO}_{3}$, of which six responded with between 10 and $100 \%$ recovery of the lost $\mathrm{BC}$, and ten samples showed no recovery or further losses of $10-40 \%$. We observed that all samples for which acidification caused some $\mathrm{BC}$ recovery were stored in PP vials, whereas samples stored in glass vials showed no recovery or even further losses. Since vial-type seems to affect the amount of BC that could be recovered after acidification, we suspect that the addition of $\mathrm{HNO}_{3}$ helped to desorb BC from the walls of the PP vials. Schwarz et al. (2012) noted a shift towards smaller particle sizes after acidification and surmised that acid helped to break up agglomerated particles. We did not observe any significant shift in the particle size distributions of samples after acidification. No distinct difference in $\mathrm{BC}$ recovery after acidification was evident based on different sample composition (AQ versus snow samples).

As in the case of fresh samples, we do not recommend acidification of stored samples or standards prior to $\mathrm{BC}$ analysis due to the variable effects of acidification on BC concentration seen in this study and the shift in particle size distribution observed by others (Schwarz et al., 2012). Similar to acid, treatment with the dispersing agent yielded varying results with BC recovery in some samples and further BC losses in others. Thus we do not recommend the use of a dispersing agent to treat fresh or stored samples. 


\section{Summary}

We compared three different nebulizer/SP2-setups to optimize the method for measuring $\mathrm{BC}$ in discrete aqueous, namely snow and ice, samples using an SP2. Both the jet (Apex Q) and ultrasonic (CETAC) nebulizer were found to be suitable for ice core analysis because they require small sample volumes of a few milliliters, whereas the Collisontype requires more than $50 \mathrm{~mL}$ sample. The nebulizing efficiency in the $\mathrm{BC}$ particle diameter range expected in snow and ice samples $(100-1000 \mathrm{~nm})$ is least size-dependent for the Apex Q. However, the air and liquid flows can only be monitored continuously with the CETAC. For all nebulizertypes we recommend an external calibration with $\mathrm{BC}$ standards for the determination of the $\mathrm{BC}$ mass concentration in unknown aqueous samples. The choice of the BC-like standard material is crucial since it was found to potentially introduce large uncertainties into the determination of the $\mathrm{BC}$ mass concentrations of an unknown aqueous BC sample. Aquablack, Cabojet and flame soot are not recommended as external calibration standards because the sensitivity of the SP2 to their BC-type is not known, thus introducing a difference of a factor of $\sim 1.8$ between possible external calibration values. Furthermore, $\sim 50 \%$ or more of the $\mathrm{BC}$ mass in Aquablack and Cabojet is associated with $\mathrm{BC}$ core sizes below the lower detection limit of the SP2 which results in an overestimation of the $\mathrm{BC}$ concentration in the analyzed sample. The SP2 sensitivity to AQ and fullerene soot is known and their main mass is within the detection limits of the SP2. This implies that for a nebulizer with a size-independent efficiency such as the Apex Q either AQ or fullerene soot can be used for external calibration. If a nebulizer with a strongly size-dependent efficiency such as the CETAC is used, it is in some cases better to use AQ and in others better to use fullerene soot, depending on which standard best matches the shape of the $\mathrm{BC}$ mass size distribution of the sample. We chose AQ to prepare the aqueous BC standards because (1) it does not exhibit any batch-to-batch variability of the corresponding internal SP2 calibration curves like fullerene soot does (Gysel et al., 2011; Laborde et al., 2012) and (2) it is easy to weigh, suspend and dilute.
We further investigated different treatments for fresh discrete snow and ice samples, the effect of sample storage and the best method to recover BC in stored samples. The samples can be kept in PP vials, which are easy to handle and are low-cost. Prior to analysis the samples should be sonicated for $25 \mathrm{~min}$ and then immediately be analyzed while being stirred with a magnetic stir bar. Acidification is not recommended. The samples should best stay frozen until just prior to analysis. If this cannot be fulfilled, the samples are best kept in glass vials at a cold temperature $\left(\sim 2{ }^{\circ} \mathrm{C}\right)$, although this might lead to BC losses. Refreezing or acidifying samples that need to be stored should be avoided. Further, the recovery of $\mathrm{BC}$ in stored samples cannot be improved by the use of acid or a dispersing agent. 


\section{Appendix A: Instrumental setup}

Figure A1 displays the instrumental setup of the three differ-

ent nebulizer/SP2-systems.

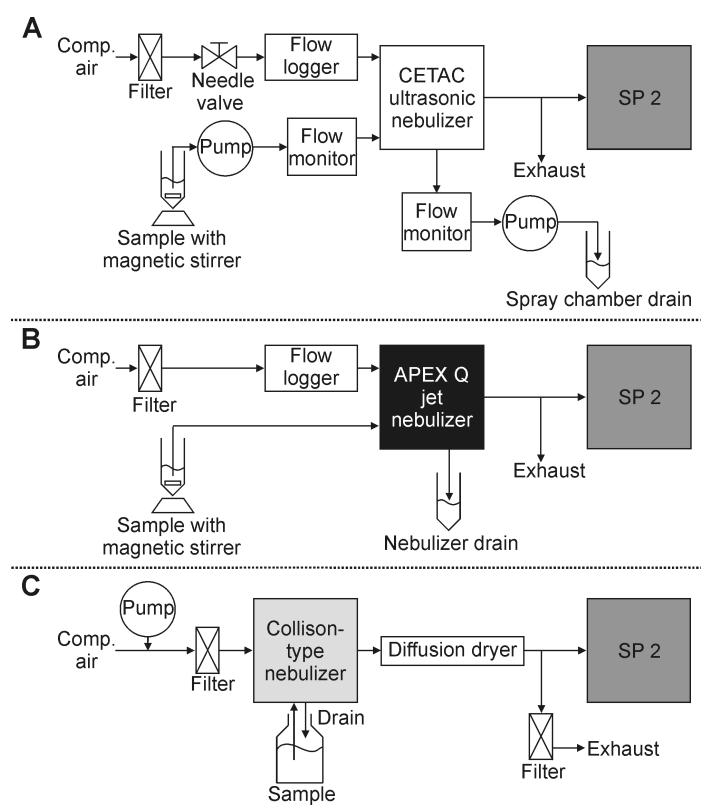

Figure A1. Instrumental setup for black carbon analysis of aqueous samples with the SP2: (A) ultrasonic (CETAC), (B) jet (Apex Q) and (C) Collison-type (PSI, built in-house) setup. Comp. air stands for compressed air.

\section{Appendix B: BC standards}

In Table B1 the various BC materials are given with their properties.

Table B1. Various BC materials mentioned in this manuscript.

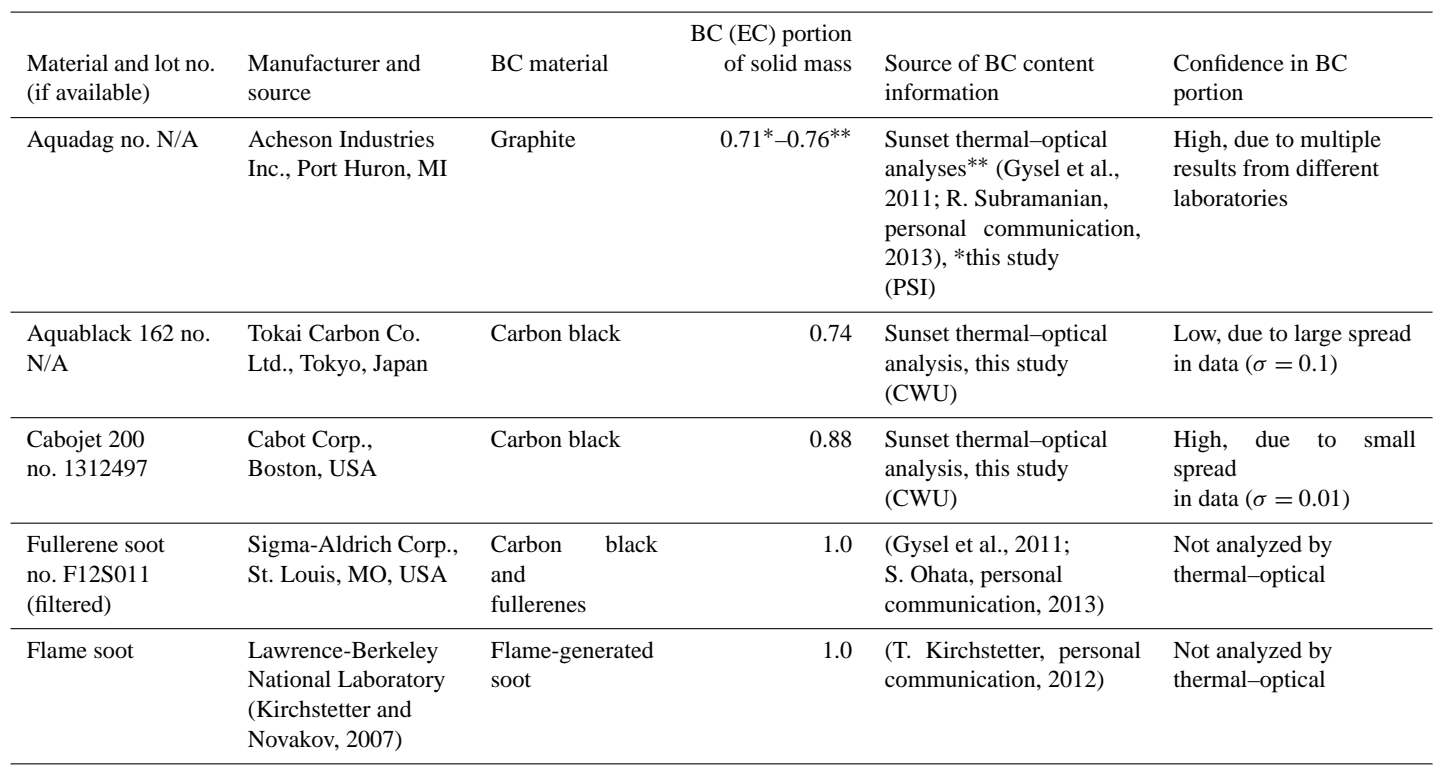



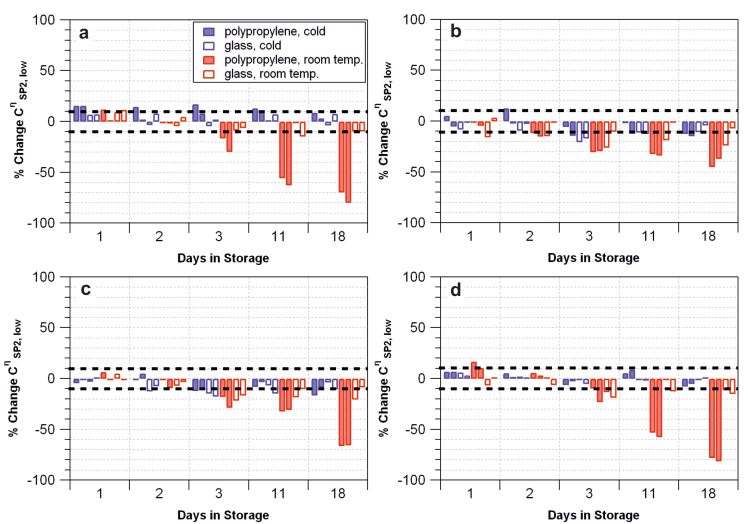

Figure C1. BC concentrations in (a) environmental snow, (b) AQ $\sim 15 \mu \mathrm{g} \mathrm{L}^{-1}$, (c) $\mathrm{AQ} \sim 10 \mu \mathrm{g} \mathrm{L}^{-1}$ and (d) AQ $\sim 3 \mu \mathrm{g} \mathrm{L}^{-1}$ samples tracked for 18 days in various storage conditions. The bars express the $\mathrm{BC}$ concentration on a given day as a percentage of the original BC concentration (before any losses due to storage; not shown). Each bar represents one sample. Black dotted lines indicate the repeatability of the SP2, assuming no sample changes.

\section{Appendix C: Sample storage}

Here we present in greater detail the results of the storage experiments discussed in the main text. Note that these storage tests were conducted with the CETAC/SP2-setup, so were subject to the nebulizer efficiency issues described in Sect. 3.1.1.
Samples were stored in polypropylene (PP) and glass vials at 25 and $2{ }^{\circ} \mathrm{C}$ and monitored over time. Teflon vials were not used in the experiment because samples stored in Teflon vials did not nebulize properly after sonication. Sample stability for AQ and environmental snow samples over an 18-day period suggests that storing samples at $25^{\circ} \mathrm{C}$ in $\mathrm{PP}$ vials results in substantial $\mathrm{BC}$ losses compared to storage in glass vials or storage at a cold temperature (Fig. C1). Samples stored in glass vials at cold temperatures remained near stable for 18 days.

In addition, these experiments indicate that the magnitude of $\mathrm{BC}$ losses in storage may be related to sample concentration. After 18 days, AQ samples stored in PP vials at $25^{\circ} \mathrm{C}$ showed 80,65 and $40 \%$ losses for low-concentration $\left(\sim 2 \mu \mathrm{g} \mathrm{L}^{-1}\right)$, medium-concentration $\left(\sim 8 \mu \mathrm{g} \mathrm{L}^{-1}\right)$ and highconcentration $\left(\sim 14 \mu \mathrm{g} \mathrm{L}^{-1}\right)$ samples, respectively (Fig. $\left.\mathrm{C} 1\right)$. This result would imply that the magnitude of losses is higher for low-concentration samples compared to highconcentration samples, but we caution that the total BC mass lost in the low-concentration samples $\left(\sim 1 \mu \mathrm{g} \mathrm{L}^{-1}\right.$ equivalent) is less than the mass of $\mathrm{BC}$ lost in the mediumand high-concentration samples ( $\sim 3 \mu \mathrm{g} \mathrm{L}^{-1}$ equivalent). It seems that while $\mathrm{BC}$ losses may be proportionally higher for low-concentration samples, total BC mass lost in storage is greater in samples that are more concentrated. This would imply that relative differences between samples may appear smaller than they actually are if the samples have undergone $\mathrm{BC}$ losses in storage. 


\section{The Supplement related to this article is available online at doi:10.5194/amt-7-2667-2014-supplement.}

Acknowledgements. The authors would like to thank J. P. Schwarz for providing a batch of fullerene soot and PSLs from Polyscience Inc., Warrington, PA, USA, and T. Kirchstetter for providing a batch of flame soot.

Edited by: J. Abbatt

\section{References}

Baumgardner, D., Popovicheva, O., Allan, J., Bernardoni, V., Cao, J., Cavalli, F., Cozic, J., Diapouli, E., Eleftheriadis, K., Genberg, P. J., Gonzalez, C., Gysel, M., John, A., Kirchstetter, T. W., Kuhlbusch, T. A. J., Laborde, M., Lack, D., Müller, T., Niessner, R., Petzold, A., Piazzalunga, A., Putaud, J. P., Schwarz, J., Sheridan, P., Subramanian, R., Swietlicki, E., Valli, G., Vecchi, R., and Viana, M.: Soot reference materials for instrument calibration and intercomparisons: a workshop summary with recommendations, Atmos. Meas. Tech., 5, 1869-1887, doi:10.5194/amt-51869-2012, 2012.

Bisiaux, M. M., Edwards, R., McConnell, J. R., Albert, M. R., Anschütz, H., Neumann, T. A., Isaksson, E., and Penner, J. E.: Variability of black carbon deposition to the East Antarctic Plateau, 1800-2000 AD, Atmos. Chem. Phys., 12, 3799-3808, doi:10.5194/acp-12-3799-2012, 2012a.

Bisiaux, M. M., Edwards, R., McConnell, J. R., Curran, M. A. J., Van Ommen, T. D., Smith, A. M., Neumann, T. A., Pasteris, D. R., Penner, J. E., and Taylor, K.: Changes in black carbon deposition to Antarctica from two high-resolution ice core records, 1850-2000 AD, Atmos. Chem. Phys., 12, 4107-4115, doi:10.5194/acp-12-4107-2012, 2012 b.

Bond, T. C., Doherty, S. J., Fahey, D. W., Forster, P. M., Berntsen, T., DeAngelo, B. J., Flanner, M. G., Ghan, S., Kärcher, B., Koch, D., Kinne, S., Kondo, Y., Quinn, P. K., Sarofim, M. C., Schultz, M. G., Schulz, M., Venkataraman, C., Zhang, H., Zhang, S., Bellouin, N., Guttikunda, S. K., Hopke, P. K., Jacobson, M. Z., Kaiser, J. W., Klimont, Z., Lohmann, U., Schwarz, J. P., Shindell, D., Storelvmo, T., Warren, S. G., and Zender, C. S.: Bounding the role of black carbon in the climate system: A scientific assessment, J. Geophys. Res.-Atmos., 118, 5380-5552, doi:10.1002/jgrd.50171, 2013.

Clarke, A. D. and Noone, K. J.: Soot in the Arctic snowpack: A cause for perturbations in radiative transfer, Atmos. Environ., 1967, 19, 2045-2053, 1985.

Cross, E. S., Onasch, T. B., Ahern, A., Wrobel, W., Slowik, J. G., Olfert, J., Lack, D. A., Massoli, P., Cappa, C. D., Schwarz, J. P., Spackman, J. R., Fahey, D. W., Sedlacek, A., Trimborn, A., Jayne, J. T., Freedman, A., Williams, L. R., Ng, N. L., Mazzoleni, C., Dubey, M., Brem, B., Kok, G., Subramanian, R., Freitag, S., Clarke, A., Thornhill, D., Marr, L. C., Kolb, C. E., Worsnop, D. R., and Davidovits, P.: Soot particle studies - instrument intercomparison - project overview, Aerosol Sci. Technol., 44, 592$611,2010$.
Dou, T., Xiao, C., Shindell, D. T., Liu, J., Eleftheriadis, K., Ming, J., and Qin, D.: The distribution of snow black carbon observed in the Arctic and compared to the GISS-PUCCINI model, Atmos. Chem. Phys., 12, 7995-8007, doi:10.5194/acp-12-79952012, 2012.

Elemental Scientific Inc.: Apex Q High Sensitivity Sample Introduction System, Product Overview, available at: http://www. icpms.com/pdf/ApexQ-ESI.pdf, last access: 10 December, 2013.

Flanner, M. G., Zender, C. S., Randerson, J. T., and Rasch, P. J.: Present-day climate forcing and response from black carbon in snow, J. Geophys. Res.-Atmos., 112, D11202, doi:10.1029/2006JD008003, 2007.

Gysel, M., Laborde, M., Olfert, J. S., Subramanian, R., and Gröhn, A. J.: Effective density of Aquadag and fullerene soot black carbon reference materials used for SP2 calibration, Atmos. Meas. Tech., 4, 2851-2858, doi:10.5194/amt-4-2851-2011, 2011.

Kaspari, S. D., Schwikowski, M., Gysel, M., Flanner, M. G., Kang, S., Hou, S., and Mayewski, P. A.: Recent increase in black carbon concentrations from a Mt. Everest ice core spanning 1860-2000 AD, Geophys. Res. Lett., 38, L04703, doi:10.1029/2010GL046096, 2011.

Kirchstetter, T. W. and Novakov, T.: Controlled generation of black carbon particles from a diffusion flame and applications in evaluating black carbon measurement methods, Atmos. Environ., 41, 1874-1888, 2007.

Laborde, M., Mertes, P., Zieger, P., Dommen, J., Baltensperger, U., and Gysel, M.: Sensitivity of the Single Particle Soot Photometer to different black carbon types, Atmos. Meas. Tech., 5, 10311043, doi:10.5194/amt-5-1031-2012, 2012.

Lavanchy, V. M. H., Gäggeler, H. W., Schotterer, U., Schwikowski, M., and Baltensperger, U.: Historical record of carbonaceous particle concentrations from a European high-alpine glacier (Colle Gnifetti, Switzerland), J. Geophys. Res., 104, 21227-21236, 1999.

McConnell, J. R., Edwards, R., Kok, G. L., Flanner, M. G., Zender, C. S., Saltzman, E. S., Banta, J. R., Pasteris, D. R., Carter, M. M., and Kahl, J. D. W.: 20th-Century Industrial Black Carbon Emissions Altered Arctic Climate Forcing, Science, 317, 13811384, doi:10.1126/science.1144856, 2007.

Moteki, N. and Kondo, Y.: Effects of mixing state on black carbon measurements by laser-induced incandescence, Aerosol Sci. Technol., 41, 398-417, 2007.

Moteki, N. and Kondo, Y.: Dependence of laser-induced incandescence on physical properties of black carbon aerosols: Measurements and theoretical interpretation, Aerosol Sci. Technol., 44, 663-675, 2010.

Ohata, S., Moteki, N., and Kondo, Y.: Evaluation of a method for measurement of the concentration and size distribution of black carbon particles suspended in rainwater, Aerosol Sci. Technol., 45, 1326-1336, doi:10.1080/02786826.2011.593590, 2011.

Ohata, S., Moteki, N., Schwarz, J., Fahey, D., and Kondo, Y.: Evaluation of a Method to Measure Black Carbon Particles Suspended in Rainwater and Snow Samples, Aerosol Sci. Technol., 47, 1073-1082, doi:10.1080/02786826.2013.824067, 2013. 
Schwarz, J. P., Gao, R. S., Fahey, D. W., Thomson, D. S., Watts, L. A., Wilson, J. C., Reeves, J. M., Darbeheshti, M., Baumgardner, D. G., Kok, G. L., Chung, S. H., Schulz, M., Hendricks, J., Lauer, A., Kärcher, B., Slowik, J. G., Rosenlof, K. H., Thompson, T. L., Langford, A. O., Loewenstein, M., and Aikin, K. C.: Single-particle measurements of midlatitude black carbon and light-scattering aerosols from the boundary layer to the lower stratosphere, J. Geophys. Res., 111, D16207, doi:10.1029/2006JD007076, 2006.

Schwarz, J. P., Doherty, S. J., Li, F., Ruggiero, S. T., Tanner, C. E., Perring, A. E., Gao, R. S., and Fahey, D. W.: Assessing Single Particle Soot Photometer and Integrating Sphere/Integrating Sandwich Spectrophotometer measurement techniques for quantifying black carbon concentration in snow, Atmos. Meas. Tech., 5, 2581-2592, doi:10.5194/amt-5-2581-2012, 2012.

Schwarz, J. P., Gao, R. S., Perring, A. E., Spackman, J. R., and Fahey, D. W.: Black carbon aerosol size in snow, Sci. Rep. 3: 1356, doi:10.1038/srep01356, 2013.

Slowik, J. G., Cross, E. S., Han, J. H., Davidovits, P., Onasch, T. B., Jayne, J. T., Williams, L. R., Canagaratna, M. R., Worsnop, D. R., Chakrabarty, R. K., Moosmüller, H., Arnott, W. P., Schwarz, J. P., Gao, R.-S., Fahey, D. W., Kok, G. L., and Petzold, A.: An inter-comparison of instruments measuring black carbon content of soot particles, Aerosol Sci. Technol., 41, 295-314, 2007.
Soto-García, L. L., Andreae, M. O., Andreae, T. W., Artaxo, P., Maenhaut, W., Kirchstetter, T., Novakov, T., Chow, J. C., and Mayol-Bracero, O. L.: Evaluation of the carbon content of aerosols from the burning of biomass in the Brazilian Amazon using thermal, optical and thermal-optical analysis methods, Atmos. Chem. Phys., 11, 4425-4444, doi:10.5194/acp-11-44252011, 2011.

Stephens, M., Turner, N., and Sandberg, J.: Particle identification by laser-induced incandescence in a solid-state laser cavity, Appl. Opt., 42, 3726-3736, 2003.

Sterle, K. M., McConnell, J. R., Dozier, J., Edwards, R., and Flanner, M. G.: Retention and radiative forcing of black carbon in eastern Sierra Nevada snow, The Cryosphere, 7, 365-374, doi:10.5194/tc-7-365-2013, 2013.

Torres, A., Bond, T. C., Lehmann, C. M. B., Subramanian, R., and Hadley, O. L.: Measuring Organic Carbon and Black Carbon in Rainwater: Evaluation of Methods, Aerosol Sci. Technol., 15, 239-250, doi:10.1080/02786826.2013.868596, 2014.

Wang, M., Xu, B., Zhao, H., Cao, J., Joswiak, D., Wu, G., and Lin, S.: The influence of dust on quantitative measurements of black carbon in ice and snow when using a thermal optical method, Aerosol Sci. Technol., 46, 60-69, 2012. 